\title{
The Nutritional Facts of Bamboo Shoots have a Potential and Prospects for Utilization as a Health Food: A Review
}

\author{
Pooja Singh ${ }^{1}$, Mamta Rathore ${ }^{2}$, H.G. Prakash ${ }^{3}$
}

10.18805/ajdfr.DR-1586

\begin{abstract}
In Indian tradition, bamboo shoot plays an important role in the traditional food of North East State of India. In India, it is used in the traditional food name as ushoi, soibum, rep, mesu, eup, hirring, etc. In the market, this crop fibre is applied in the bakery and meat products. It has lots of health benefits to the human because it is nutritionally important that contain huge amount of protein, carbohydrate, vitamin, fibre, minerals and very trace amount of fat. Mostly its shoot may be consumed as a food either in fresh form or canned form. The main aimed to study the bamboo shoot could be helpful in mitigating the problem of malnutrition and food security and boost immune system are the major challenges for humanity which facing during Covid-19 pandemic situation. The role of bamboo is increasing day-to-day. Due to the present of phytosterols and rich amount of fibre, it becomes nutraceuticals and apply as natural medicine in several diseases. In recent time, the people are aware to improve their immunity to fight against such type of diseasesto improve the digestion and appetite and recover weight or loss, to cure cardiovascular diseases (CVD) and cancer. The part of this crop mainly shoot has important role in the anticancer, antibacterial and also antiviral diseases. The bamboo smell is very strong due to the presence of phenolic compounds. In Tripura, new event are discovered such as bamboo shoot fortified cookies as a healthy snack. So that its unique characteristics, bamboo is known as miracle plant and green gold. It play an important role in the secondary metabolize formation, so that its taste is slightly acidic. Various bamboo shoot processing methods, effect of cooking, technological methods for removal of toxic constituent in shoots have also been discussed.
\end{abstract}

Key words: Antibacterial, Anticancer, Antiviral activity, Bamboo fibre, Cynogenic glycosides, Functional foods, Health foods, Neutraceuticals, Phytostrols.

Bamboos, belonging to the family Poaceae, are popularly known for their industrial uses and one of the most multiutility forest tree grasses. They are known to have most ecological important plants and the wide range of extensive uses they have for humans. Bamboos are most valuable as an alternative crop with multiple uses and benefits and its contributing individual with various living resources $A$. Lewington, (1999). Because of its multifarious utility, both in the traditional way for the rural people as well as in modern society, bamboo is applicable for paper making, handicraft industry, house construction and making furniture, water pipes, storage vessels as well as other crucial household items. Bamboos provide food, shelter, medicine, raw materials for construction, wood substitute and paper and pulp for industry. They are also used for making furniture, handicrafts, containers, tool handles, poles, musical instruments, bows and arrows, boats, rafts, fishing poles and so on.

The leaves have been used as fodder for livestock by the Japanese for hundreds of years. In different countries bamboos address in different names such as Chinese called bamboos as "Friend of people", Indians as "Green Gold." The properties of bamboo shoots were recorded in the pharmaceutical text book "It's slightly cold, sweet, nontoxic and it quenches thirst and found benefits of bamboo extract in our circulatory system and can be served as a daily dish" Yuming and Jiru (1999). In addition to their multiple application, juvenile shoots value as prominent food items. Bamboo shoots are rich source of dietary fibre which
1Department of Food Science and Nutrition, Directorate of Research, C.S. Azad University of Agriculture and Technology, Kanpur-208 002, Uttar Pradesh, India.

${ }^{2}$ Department of Biochemistry, Directorate of Research, C.S. Azad University of Agriculture and Technology, Kanpur-208 002, Uttar Pradesh, India.

${ }^{3}$ Department of Dairy Science, Directorate of Research, C.S. Azad University of Agriculture and Technology, Kanpur-208 002, Uttar Pradesh, India.

Corresponding Author: Pooja Singh, Department of Food Science and Nutrition, C.S. Azad University of Agriculture and Technology, Kanpur-208 002, Uttar Pradesh, India. Email: ps794743@gmail.com

How to cite this article: Singh, P., Rathore, M. and Prakash, H.G. (2021). The Nutritional Facts of Bamboo Shoots have a Potential and Prospects for Utilization as a Health Food: A Review. Asian Journal of Dairy and Food Research. 40(4): 388-397. DOI: $10.18805 /$ ajdfr.DR-1586.

Submitted: $05-10-2020 \quad$ Accepted: 24-03-2021 Online: 30-07-2021

possesses number of health benefits as it controls blood pressure, hypertension and obesity as well as protect our body from coronary diseases and carcinogens, this survey conducted by Kalita and Dutta, (2012). Park and John, (2012) reported that in Northeast states bamboo shoots are taken either fresh at the time of harvesting season or dried, fermented or pickled forms during off season. One can find evidence about the benefits of eating bamboo shoots. In Japan, bamboo is popular as "King of Forest Vegetables". 
Due to its delicious taste and rich nutritional value, in China, people knowing bamboo shoots a treasure dish in the Tang Dynasty (618 to 907) and first written record about these shoots in human history.

\section{Global scenario of bamboo shoots}

The edible bamboo shoots contain strong unique taste and flavor. Due to present of typical aroma, there are abundant in bio-flavonoids and antioxidant Hamman, (2008), which accelerate excellent storage stability Park, (2010). Bamboo shoots used as a part of regular cookery and are consumed in various forms in many parts of the world Daphne (1996), Tamang et al. (1988), Caitlin and Miles, (2000), Pande and Pandey, (2008). Although, bamboo grows naturally or is cultivated in orchard and farms and is one of the underestimated natural resources in the international scenario. In international markets, China earns 8,400 million whereas India earns rupees every year from export of edible bamboo shoots, however USA import of around 45,000 tonnes accounting for $14.5 \%$ of the total world import Lobovikov, (2003). Thailand, India, China and Taiwan used bamboo shoots for domestic consumption as food items Daphne, (1996). Every year USA imports 30,000 tonnes of canned bamboo shoots, respectively the two major species of edible bamboo shoots which are famous in Thailand and Taiwan such as Dendrocalamus lactiferous and Bambusa oldhami Tai (1985), Fu et al. (1798). Taiwan consumes about 80,000 tonnes of bamboo shoots annually which value of 2,600 million Indian rupees, the total covering 30,000 ha of land of bamboo shoots under growing condition, producing total 386,000 tonnes of bamboo shoots per year Tai, (1985). At present, over two million tonnes of edible bamboo shoots are consumed in the world in each year Yang et al. (2008), Vaiphei, (2005). In India, the market potential of bamboo shoots is estimated at present at 460 million Indian rupees, which will be increase day by day to 26,000 million in 2015 . Thus enabling five million families of artisans and farmers crossing the poverty line Farooquee et al. (2007).

\section{Role of bamboo shoots on the basis of its nutritional composition}

In different bamboo species, the nutritional value of edible shoots are different and it has been proved by several workers. Bamboo shoots have enormous health benefits due to its high content of protein ranging from $1.49 \mathrm{~g} / 100 \mathrm{~g}$ to $4.04 \mathrm{~g} / 100 \mathrm{~g}$ on fresh weight basis, amino acids, carbohydrates, many important minerals consisting mainly of potassium (K), calcium (Ca), manganese, zinc, chromium, copper, iron ( $\mathrm{Fe}$ ), plus lower amounts of phosphorus $(\mathrm{P})$ and selenium Shi and Yang, (1992), Nirmala et al. (2007) and vitamins. A newly collected bamboo shoots have good profile of thiamine, niacin, vitamin A, vitamin B6 and vitamin E. Also the bamboo shoots based diet are rich source of fat, sugar, fiber and inorganic salts. They contain 17 amino acids, 8 of which are essential for the human body Qiu, (1992); Ferreira and others, (1995). Tyrosine amounts to $5.6 \%$ to $6.5 \%$ of the total amino acid content Kozukue and others,
(1998). Fat content is comparatively low $(0.23 \%$ to $0.74 \%)$ and the shoots contain important essential fatty acids. The total sugar content, $2.4 \%$ on average, is lower than that of other vegetables. The water content is $91 \%$ or more. Major advances of bamboo shoots have been seen in areas of production and processing and studied conducted by some workers in the analysis of nutrient components as well as data interpretation. Bamboo shoots are important unconventional sources of proteins which when incorporated in food products would improve the functional properties. Freshly shoots contain good nutritional supplements so it may be called as a new health food. This is because bamboo shoots are endowed with these health-enhancing properties.

\section{Rich in nutrients}

Fresh shoots have a high content of protein (amino acids), carbohydrate, minerals and several vitamins such as thiamine, niacin, vitamin A, vitamin B6 and vitamin E Visuphaka, (1985); Xia, (1989); Shi and Yang, (1992). And it contain rich amount of amino acids mainly tyrosine (57\% to $67 \%$ ) and average amount of arginine, histidine and leucine as amino acids. Out of 17 are essential for human body. Tyrosine worked as a major constituent of adrenals which are precursors for adrenaline which necessary for active metabolic activities for our body. Thus it also plays a major role in function of thyroid and pituitary glands which are involved in producing and regulating hormones in human body, Shi and Yang, (1992), Nirmala et al. (2007).

\section{Function as nutraceuticals}

Nutraceuticals are ordinary foods with components or ingredients imparting a specific medical or physiological benefit other than a purely nutritional effect. Bamboo shoots contain phytosterols and a high amount of fiber that can qualify as "nutraceuticals" or "natural medicines." Phytosterols have a cholesterol-lowering activity, Brufau and others, (2008). Children and women before menopause, during pregnancy or while nursing, require high amounts of Iron, Tapiero and others, (2001). This can be obtained by consumption of bamboo shoots that contain a comparatively higher amount of iron than other commonly consumed vegetables.

\section{High fiber content}

Bamboo shoots are a good source of edible fiber (6 to $8 \mathrm{~g} /$ $100 \mathrm{~g}$ fresh weight), which helps in lowering the blood cholesterol. They are neutral in taste and odor free and have no calories and fats. Bamboo fiber is available as a white powder with at least $95 \%$ fiber. A number of companies sold as such in market as high quality fiber (bamboo shoots) additives that are rich sources of dietary fiber. Presence of high fiber and phytosterols in bamboo shoot helps in reducing the fat and cholesterol level of blood, as such safe our body from modern lifestyle disease.The dietary fiber possesses number of health benefits as it controls blood pressure, hypertention and obesity, laxative properties and also protect our body from CVD and dangerous carcinogens. 
The survey conducted by Kalita and Dutta, (2012) showed that the rich dietary fiber and low fat (bamboo shoot) help in reducing the thickening of arteries maintaining the blood pressure.

\section{Low fat}

Fat content is extremely low $(0.26 \%$ to $0.94 \%)$ and the shoots contain important essential fatty acids $(2.46 \mathrm{~g} / 100 \mathrm{~g})$ that are, therefore, very good for weight-conscious and dieting people. Pork and John, (1996), conducted a study to show that bamboo shoots based diet have low serum content of total cholesterol and LDL (Low Density Lipoprotein). Regular intake of bamboo shoots reduces reproductive health related issues in female i.e. treatment of irregular menstrual cycle, heavy bleeding after delivery, infertility problems, reducing labour pain and also for inducing puberty in young female and useful in curing snake and scorpion bites. A major disadvantage that they are often advised not to consume bamboo shoot during the first trimester of pregnancy because some tribes believes that it causes abortion in pregnant women (Bao, 2006).

\section{Appetizer}

The high cellulosic content of bamboo shoots stimulates appetite. Being crisp, crunchy and tender with a sweet flavor, shoots have a unique and delicious taste that function as an appetizer. Fresh shoots of 14 species have been analyzed for their nutritive value.

Bamboo shoots content higher amount of amino acids. Out of 17 amino acids were essential for human body, Nirmala et al. (2007) Giri and Janmejay (1992) reported reduction of individual amino acids content in 300-day-old bamboo shoots of Bambusa tudla. Sharma et al. found variation in amount of protein in 9 species of bamboos studied. The carbohydrate content in two-day old shoot (1.42 $\mathrm{g} / 100 \mathrm{~g}$ fresh weight) increased to $2.46 \mathrm{~g} / 100 \mathrm{~g}$ fresh weight after 16 days, Pandey and Ojha, Nirmala et al. (2007); Bhatt et al. (2005) reported the intake of bamboo shoots on regular basis improves the lipid profile and bowel movement in young healthy women. Bamboo shoots are rich quantities of useful minerals such as potassium, phosphorus, sodium and iron. Minerals are required for the proper functioning of many useful metabolic activities of our body,

\section{Bioactive compounds}

Scientific evidence has indicated that consumption of bamboo based foods may lead to reduce risk of certain diseases such as CVD, cancer and other age-related conditions. "Bioactive compounds" are essential and nonessential compounds that occur in nature, are part of the food chain and have an effect on human health Kris-Etherton et al, (2004) and can influence metabolism, gene expression and interact with disease precursors and disease-developing mechanisms Rostagno et al, (2010). Plant food contains many bioactive compounds, these physiologically active compounds, referred to as "phytochemicals," that have significant health potentials are carotenoids, phenolic compounds (flavonoids, phytoestrogens, phenolic acids), phytosterols and phytostanols, saponins, tocotrienols, organosulfur compounds (allium compounds and glucosinolates) and non-digestible carbohydrates (dietary fiber and prebiotics). These are plant-based bioactive compounds that have been numerous health effects. Phenolic compounds (flavonoids), are present in all parts of bamboo shoots and have many antioxidant properties. Plant sterol or phytosterol is a bioactive compound both present in bamboo shoots and found in some foods such as oils, nuts and vegetables. In the same way, phytosterols as cholesterol contain a double bond and are susceptible to oxidation and are characterized by anti-carcinogenic and anti-atherogenic properties. Bamboo shoots contain varying amount of cynogen glycosides called taxiphyllin, a disadvantage that its causes cyanide poisoning seen in Mysore, India, due to regular consumption of bamboo shoot extract. The patient showed convulsion, vomiting, respiratory distress and loss of consciousness etc.

\section{Biochemical importance}

Table 1 Bamboo shoots are rich in nutrients components as high fiber content, energy ( $27 \mathrm{Kcal})$, sugars $(3 \mathrm{~g} / 100 \mathrm{gm})$, protein $(2.6 \mathrm{~g} / 100 \mathrm{~g})$, carbohydrates $(5.2 \mathrm{~g} / 100 \mathrm{~g})$, minerals viz. iron $(0.5 \mathrm{mg})$, manganese $(0.262 \mathrm{mg})$, phosphorus $(59$ $\mathrm{mg})$, potassium $(533 \mathrm{mg})$ and zinc $(1.1 \mathrm{mg})$ and vitamins such as thiamin (B1) $(0.15 \mathrm{mg})$, riboflavin (B2) $(0.07 \mathrm{mg})$, niacin $(0.6 \mathrm{mg})$ and pantothenic acid $(0.161 \mathrm{mg})$, Vitamin B6 $(0.24$ $\mathrm{mg})$, folate $(7 \mathrm{mg})$, Vitamin C $(4 \mathrm{mg})$ and Vitamin $\mathrm{E}(1 \mathrm{mg})$.

Table 2 discussed in detail about the content of nutrients composition percentage with some common vegetables such as amino acid (tyrosine), protein, carbohydrate, fibres, potassium, iron and calcium have been comparision with different varieties of bamboos (bambusa tudla,

Table 1: Nutritional value of Bamboo shoots per $100 \mathrm{gm}$.

\begin{tabular}{ll}
\hline Energy & $27 \mathrm{Kcal}$ \\
\hline Carbohydrates & $5.2 \mathrm{~g}$ \\
Sugars & $3 \mathrm{~g}$ \\
Dietary fiber & $2.2 \mathrm{~g}$ \\
Fat & $0.3 \mathrm{~g}$ \\
Protein & $2.6 \mathrm{~g}$ \\
Thiamin (B1) & $0.15 \mathrm{mg}$ \\
Riboflavin (B2) & $0.07 \mathrm{mg}$ \\
Niacin (B3) & $0.6 \mathrm{mg}$ \\
Pantothenic acid (B5) & $0.161 \mathrm{mg}$ \\
Vitamin B6 & $0.24 \mathrm{mg}$ \\
Folate (B9) & $7 \mathrm{mg}$ \\
Vitamin C & $4 \mathrm{mg}$ \\
Vitamin E & $1 \mathrm{mg}$ \\
Iron & $0.5 \mathrm{mg}$ \\
Manganese & $0.262 \mathrm{mg}$ \\
Phosphorus & $59 \mathrm{mg}$ \\
Potassium & $533 \mathrm{mg}$ \\
Zinc & $1.1 \mathrm{mg}$ \\
\hline
\end{tabular}

*Source: www.google.com. 
The Nutritional Facts of Bamboo Shoots have a Potential and Prospects for Utilization as a Health Food: A Review

Table 2: Comparison of nutrient content of freshly emerged juvenile shoots of Bambusa tulda and Dendrocalamus hamiltonii with some common vegetables.

\begin{tabular}{|c|c|c|c|c|c|c|c|c|c|}
\hline Nutrients & $\begin{array}{c}\text { Bambusa } \\
\text { tulda }\end{array}$ & $\begin{array}{c}\text { Dendrocalamus } \\
\text { hamiltonii }\end{array}$ & $\begin{array}{c}\text { Daucus } \\
\text { carota }\end{array}$ & $\begin{array}{c}\text { Raphanus } \\
\text { sativus }\end{array}$ & $\begin{array}{c}\text { Spinacea } \\
\text { oleracea }\end{array}$ & $\begin{array}{c}\text { Solanum } \\
\text { tuberosum }\end{array}$ & $\begin{array}{c}\text { Abelmoschus } \\
\text { esculentus }\end{array}$ & $\begin{array}{c}\text { Curcuma } \\
\text { sativus }\end{array}$ & $\begin{array}{r}\text { Cucurbita } \\
\text { maxima }\end{array}$ \\
\hline Amino acids (tyrosie) $\%$ & 0.365 & 0.318 & 0.020 & 0.040 & 0.03 & 0.020 & 0.03 & 0.010 & 0.020 \\
\hline Protein \% & 0.369 & 0.372 & 0.090 & 0.069 & 0.2 & 0.160 & 0.19 & 0.06 & 0.139 \\
\hline Carbohydrate\% & 0.692 & 0.55 & 1.06 & 0.34 & 0.29 & 2.260 & 0.640 & 0.25 & 0.65 \\
\hline Fats \% & 0.040 & 0.041 & 0.010 & 0.040 & 0.069 & 0.010 & 0.020 & 0.010 & 0.040 \\
\hline Fibers \% & 0.397 & 0.39 & 0.12 & 0.06 & 0.2 & 0.040 & 0.12 & 0.040 & 0.110 \\
\hline Vitamin C \% & 0.0014 & 0.0024 & 0.015 & 0.0016 & 0.0006 & 0.0004 & 0.0012 & 0.0007 & 0.0007 \\
\hline Vitamin E \% & 0.00061 & 0.00071 & 0.003 & 0.015 & 0.0281 & 0.0197 & 0.013 & 0.0032 & 0.0009 \\
\hline Potassium \% & 0.408 & 0.416 & 0.108 & 0.393 & 0.558 & 0.424 & 0.103 & 0.135 & 0.34 \\
\hline Iron \% & 0.0031 & 0.00269 & 0.001 & 0.001 & 0.0027 & 0.0008 & 0.00035 & 0.0009 & 0.0008 \\
\hline Calcium\% & 0.0040 & 0.003 & 0.08 & 0.035 & 0.009 & 0.012 & 0.056 & 0.014 & 0.021 \\
\hline Copper \% & 0.0044 & 0.00029 & 0.0001 & 0.0002 & 0.0001 & 0.00016 & 0.00011 & 0.00089 & 0.0001 \\
\hline Sodium \% & 0.0199 & 0.0093 & 0.035 & 0.039 & 0.079 & 0.011 & 0.0069 & 0.002 & 0.0056 \\
\hline Zinc \% & 0.00071 & 0.0007 & 0.00035 & 0.0003 & 0.0005 & 0.0003 & 0.00042 & 0.00023 & 0.0003 \\
\hline
\end{tabular}

${ }^{*}$ Table list of commonly used edible bamboo species in Manipur and their distribution.
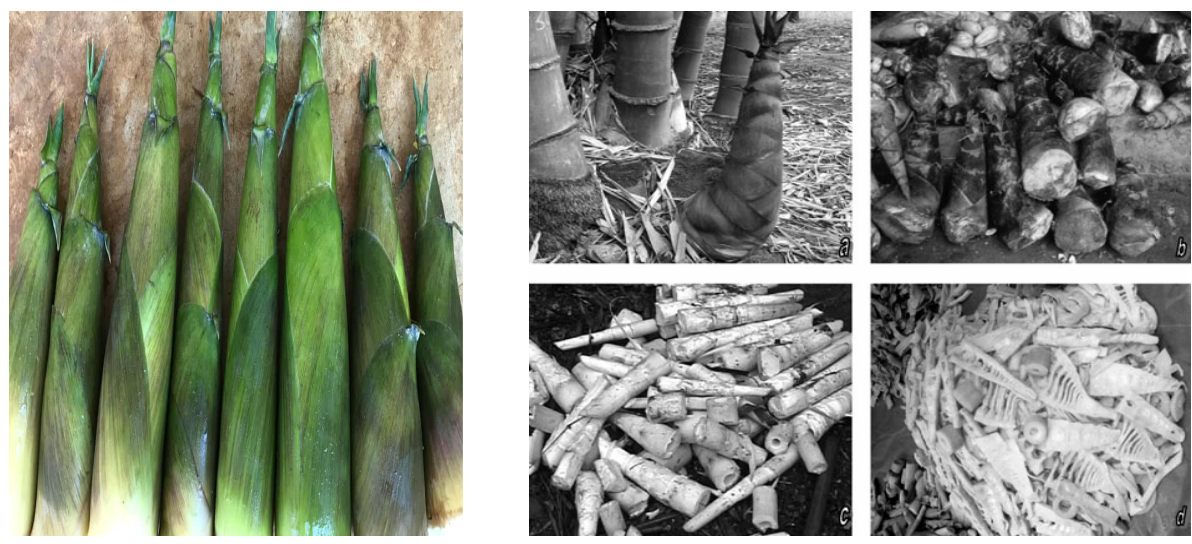

Fig 1: Fresh bamboo shoots fermented and canned shoots.

*Source: www.google.com

dendrocalamus hamiltonii, daucus carota, Raphanus sativus, spinacea oleracea, solanum tuberosum, abelmoschus esculentus, curcuma sativus, cucurbita maxima).

Fig 1 shows the fresh bamboo shoots are found in various processed forms and also used in fresh, dried and canned form in many food processed industries. Row bamboo shoots by leaching out and boiled before being used in other ways. Canning process most of toxins are also destroyed.

Fig 2 and 3 shows the structures of phenolic compounds and phytosterol present in bamboo shoots and further more discussed that Campesterol is a simplest sterol, characterized by the hydroxyl group in position C-3 of the steroid skeleton and saturated bonds throughout the sterol structure with the exception of the 5-6 double bond in the B ring. Cholesterol is a cholestanoid consisting of cholestane having a double bond at the 5,6- position as well as 3 betahydroxy group. It has a role as a human metabolite. Ergosterol is a provitamin form of vitamin $D_{2}$ and is a phytosterol consisting of ergostane having double bonds at the 5, 6, -7, 8 and 22,23-positions as well as 3 beta-hydroxy group and found in cell membranes of fungi and protozoa, serving many of the same functions that cholesterol serves in animal cells. Stigmasterol is asteroid derivative characterized by the hydroxyl group in position C-3 of the steroid skeleton and unsaturated bonds in position 5-6 of the $B$ ring, and position $22-23$ in the alkyl substituent. BSitosterol is a member of the class of phytosterols that is stigmast 5-ene substituted by a beta-hydroxy group at position 3. It is a main dietary phytosterol found in plants, may have the potential for preventing human cancer and are characterized by anticholesteremic drug and antioxidant properties. Stigmastanol is a steroid derivative characterized by the hydroxyl group in position C-3 of the steroid skeleton and a unsaturated bonds in position 5-6 of the $B$ ring.

In Fig 4-12 shows the different varieties of Bambusa tudla, Dendrocalamus hamiltonii, Daucus carota, Raphanus sativus, Spinacea oleracea, Solanum tuberosum, Abelmoschus esculentus and Curcuma sativus. Each figure shows with graph. 


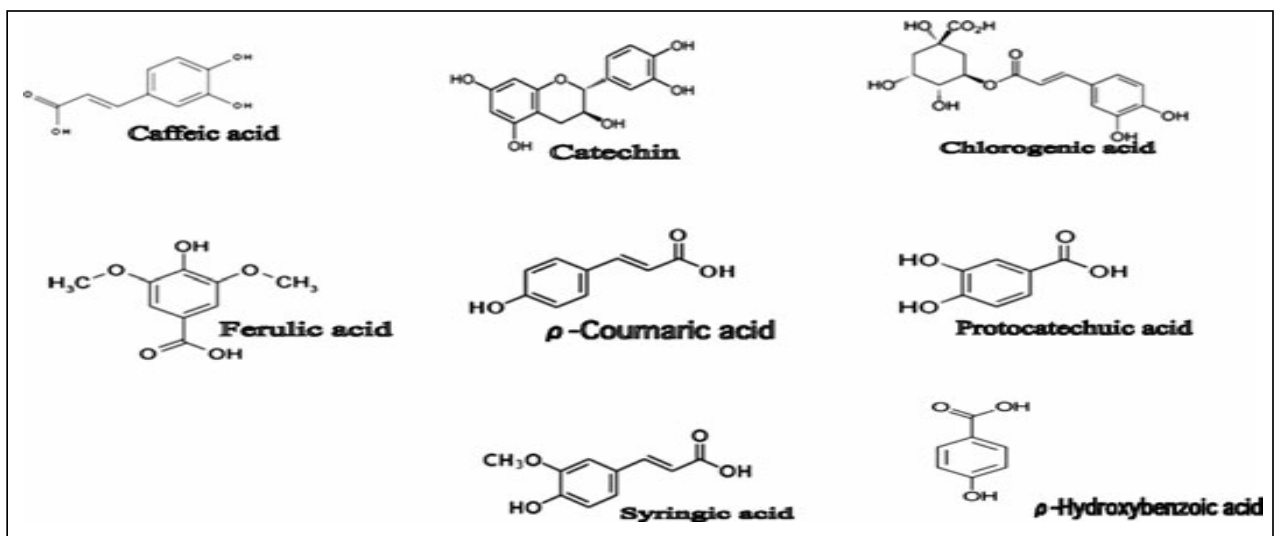

Fig 2: Structures of phenolic compounds present in bamboo shoots.

*Source: researchgate.net.

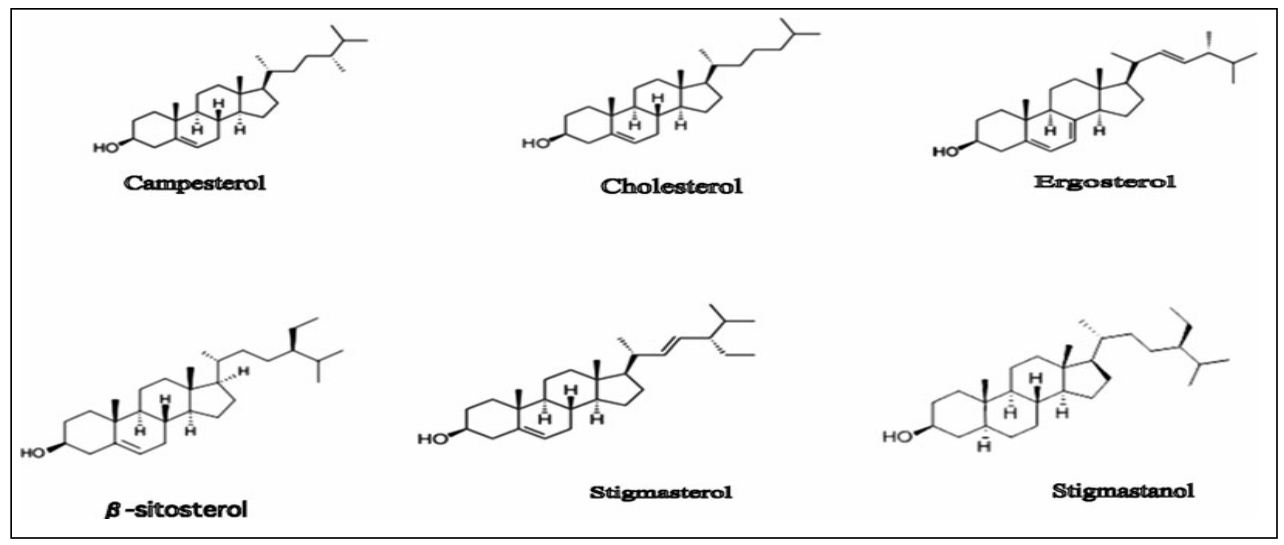

Fig 3: Phytosterols present in bamboo shoots and their corresponding structures.

*Source: Wiley Online Library.

\section{Functional properties of bamboo shoot}

In brief, shoots have some anticancer, antibacterial and antiviral activity. Due to the presence of phenolic compounds, shoots have antioxidant capacity. The increasing trends of health consciousness as well as lifestyle modification, consumers have attract of functional foods and bamboo shoots can be one of them. Bamboo shoot is not only known for providing an exotic taste appeal, but has also been explored health promoting attributes. It has been screened for anti-inflammatory effects as well as anti-fungal effects and also protected from oxidative stress, ischemic injury treatment and for its fatique and cholesterol reducing properties. Recently, its dietary fibre has many functional properties, bamboo shoots production and market status day-to-day increased.

\section{Types of bamboo shoots}

There are numerous ways bamboo shoots are available such as: fresh, fermented and canned form. The fresh shoots are used in households, by processed food makers and 5star hotels and specialty restaurants the reason are that quality, convenience and price. However, fermented shoots are less preferred by people due to their pungent smell and astringent taste.

\section{Fresh shoots}

Fresh shoots are superior in taste and texture and the nutrient especially protein, are at their peaks when shoots are juvenile form, so at this stage shoots are collected and applicable in food industries for beneficial effect of human health. For consuming fresh shoots, the fibrous portion at the basal end of the shoot is cut off and the outer hard leaf sheaths are removed. The tender portion inside near the top of the shoot can be seen as they are tender and full of flavor. After slicing, the shoots are soaked in water for 1 to 2 $\mathrm{h}$ and then boiled for half an hour to remove acridity. Now they are ready for use.

If no bitterness is present, they can be used directly as salad or stir-fried like other vegetables. The shoots can be used in different form such as pickles, frozen or salted and dehydrated etc.

\section{Fermented shoots}

Fermentation is a process to preserve food item and it also adds to the nutritional value, enrich flavor and improves pharmacological and nuetraceutical values. Different types of chemical change occur through the breakdown of carbohydrates and proteins by yeast, bacteria, or molds. This process is used for centuries in older times, in order to 
The Nutritional Facts of Bamboo Shoots have a Potential and Prospects for Utilization as a Health Food: A Review

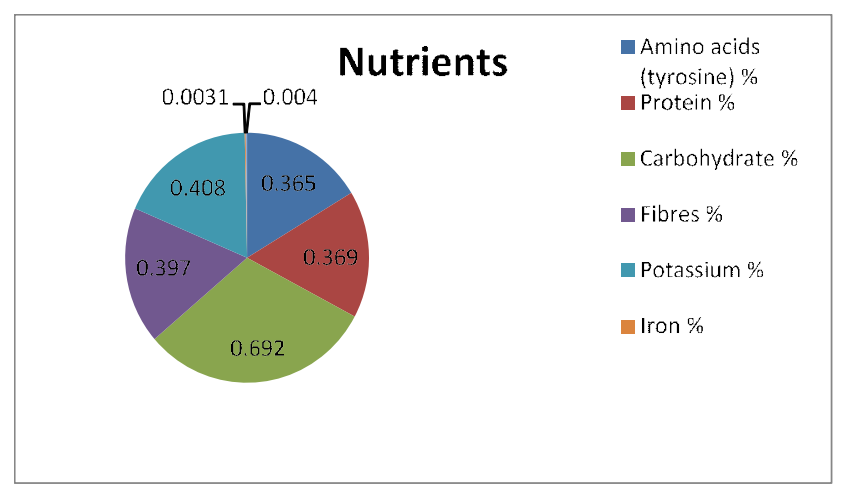

Fig 4: Bambusa tulda.

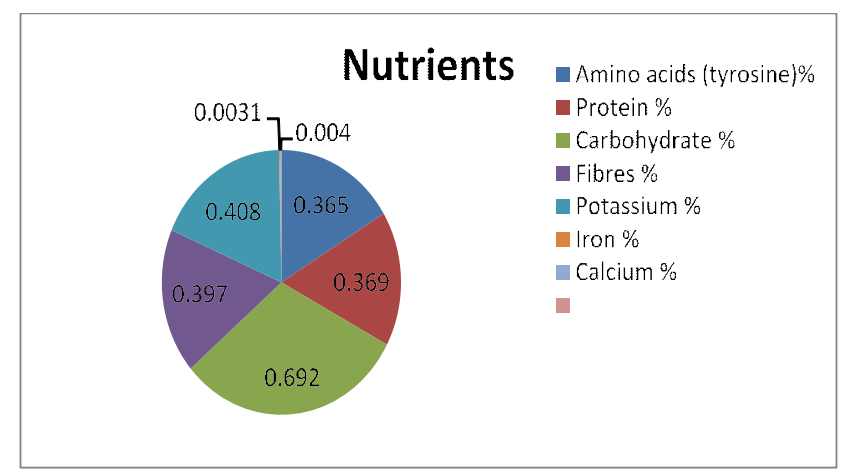

Fig 5: Dendrocalamus hamiltonii.

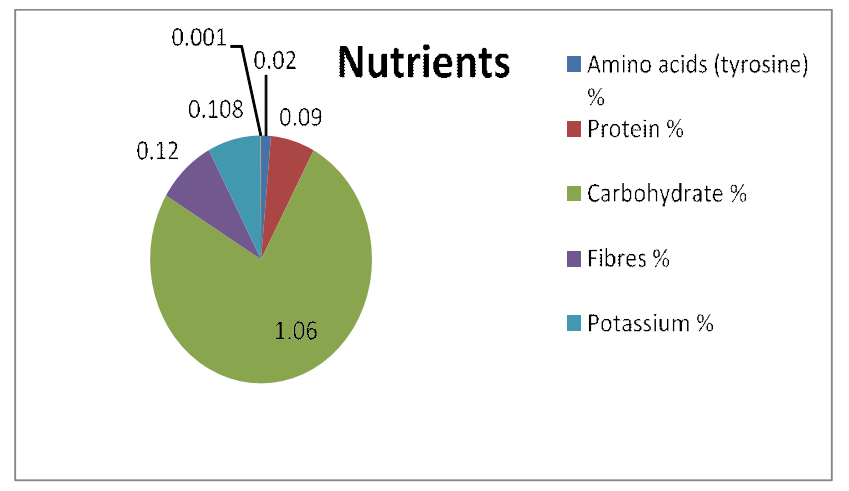

Fig 6: Daucus carota.

make and preserve certain types of food such as wine, cheese, beer, yogurt, pickles, ketchup and sauerkraut are examples of foods that are made through the process of fermentation. In each fermented food, the micro flora significantly increases the protein, vitamin and fatty acid quality. Probiotics or "good bacteria" are also formed through the process of fermentation.

Antioxidants and antimicrobial compounds have also been isolated through fermentation process. Fermented bamboo shoots sold in the market as vegetable form. Mesu is fermented shoot product which is a favourite among the people of Sikkim and Darjeeling as locally made pickle.

\section{Canned shoots}

The emerging time bamboo shoots are commonly available in the canned form in the markets. The Japanese were the

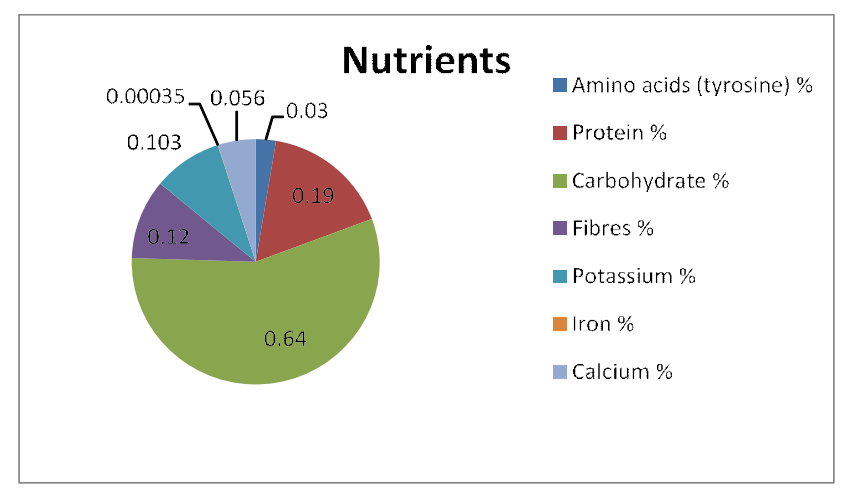

Fig 7: Raphanus sativus.

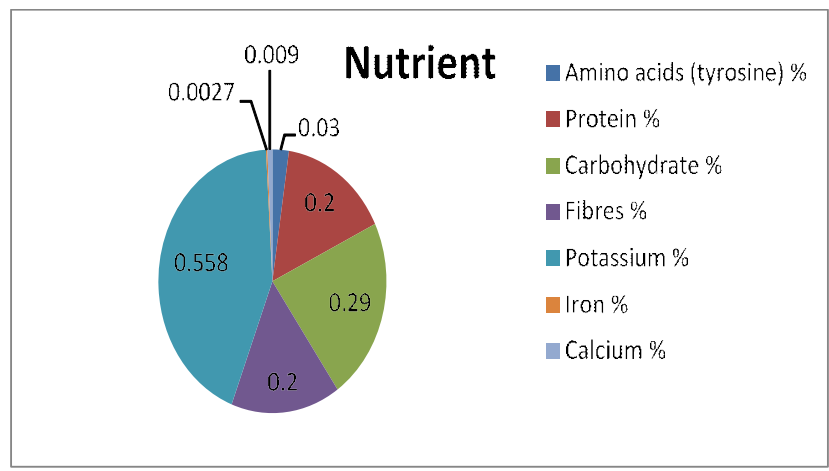

Fig 8: Spinacea oleracea.

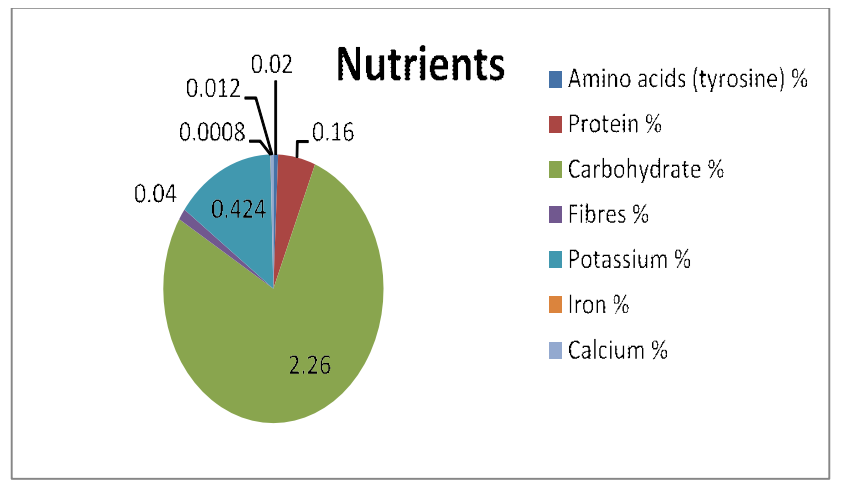

Fig 9: Solanum tuberosum.

first to develop and use modern technology for the processing of fresh shoots. The shoots are cut in various ways into halves, thin sliced, stripped, diced, or canned as whole after processing. For developing canned bamboo shoot, different processing technique involves to obtain good quality products. First involves boiling the sliced bamboo shoots in water for about $4 \mathrm{~h}$ or for 40 to $60 \mathrm{~min}$ at $120^{\circ} \mathrm{C}$, then cooling and storage in brine solution containing usually around $5 \%$ to $10 \% \mathrm{NaCl}$ or more, depending on the species used and $1 \%$ citric acid. In this way, in the market, processed canned products are seen in cans or retort pouches. Cans contain processed fresh materials, while retort pouches contain processed salted or cured materials. There are more than 80 companies manufacturing 49 products of canned shoots under various brand names in the world. China, 
The Nutritional Facts of Bamboo Shoots have a Potential and Prospects for Utilization as a Health Food: A Review

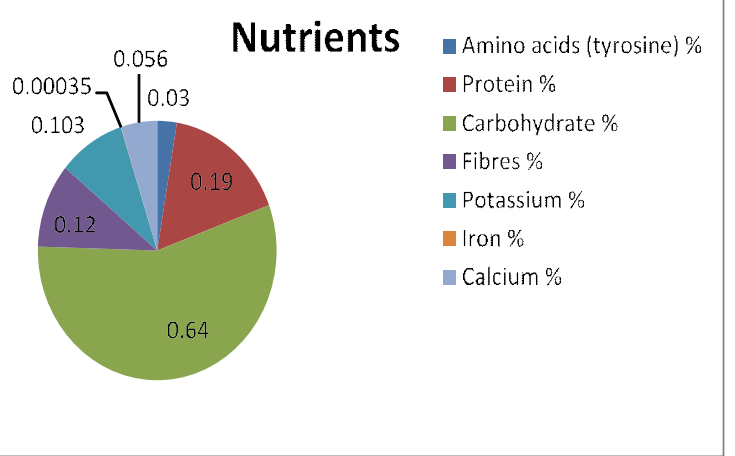

Fig 10: Abelmoschus esculentus.

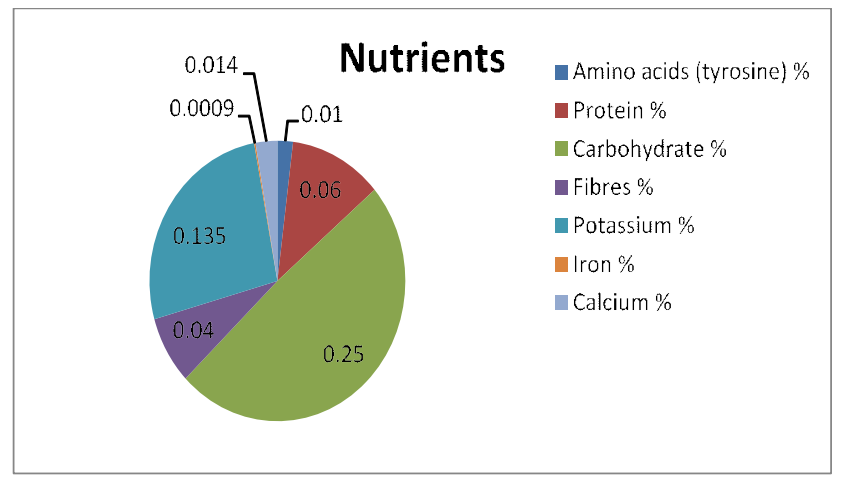

Fig 11: Curcuma sativus.

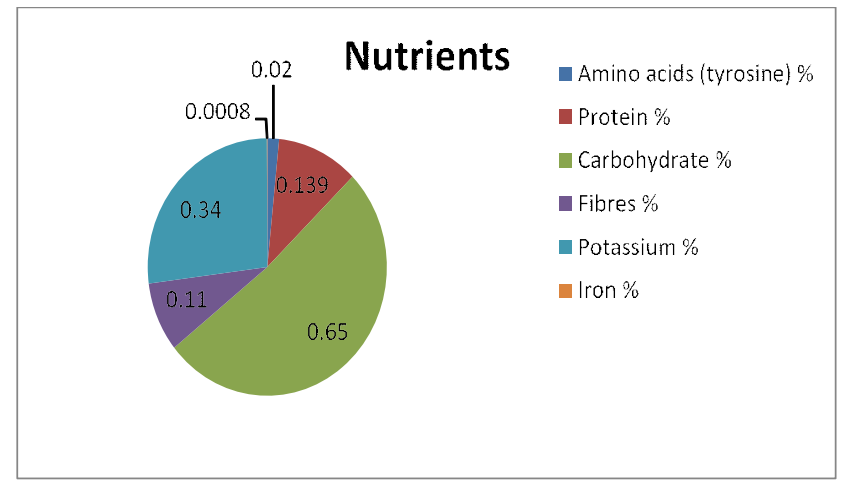

Fig 12: Curcurbita maxima.

*Source: Fig 4-12 using Table 2.

Taiwan and Thailand are the leading countries supplying canned bamboo products to the world market. The canned shoots find markets in Singapore, Malaysia, Bhutan and Thailand. The drawbacks of canned shoots are poor shape, loss of aroma and crunchiness and shelf life in canned product is also less and decrease of nutrient component, especially vitamins and minerals, during canning Nirmala et al, (2008).

\section{Bamboo shoot recipes and food products}

Bamboo shoots have been integrated in the North and South Indian cuisine, some around 12 popular inter-continental dishes prepared from bamboo shoot like-halwa, chutney, pulao, curry, bhaji, etc. have been popularized by
Engineering Resource Group, Bangalore (NMBA, 2009). Bamboo shoots used as common ingredient in Chinese dishes. Bamboo shoots product commercially available in China, Japan, Thailand and Malaysia available in different form such as canned, fermented, bamboo pickle, bamboo shoot based powder, bamboo shoot juice and bamboo beer (pre-prepared from bamboo clums), bamboo wine, bamboo tea, vinegar and charcoal etc., Knechtges, (1986). Boiled and fresh bamboo shoots are exported in various part of the world where they are processed. The exportation of dried bamboo shoots banned by local authorities, Greijmans et al. (2007). Light-colored, cone- shaped bamboo shoots are sold in Chinese or oriental provision stores and supermarkets. Crisp shoots of bamboo which make a sweet, crunch to dishes especially stir-fries are very popular homestyle dish in Chinese cuisine, Chinese food recipes,Bamboo shoots are eaten as a curry, pickle, soup, or juice in different communities, Fu and Singh et al. (2009).

\section{Bamboo shoot based powder}

Bamboo shoots contains considerable amount of carbohydrate and dietary fibres. When boiled the bamboo shoots, its polysaccharides become hydrolyzed into simple sugars and gives sweet taste to the shoots (Kumbhare and Bhargava 2007). Dried bamboo shoot powder contain low moisture so that it may be direct uses into various dry food items and preparing chutney and beverages. The key advantages of using dried bamboo shoot based powder may include as free-flowing, ease of handling and weighing, reduced storage space, ease of cleaning and sanitary aspects. Bamboo shoot based powder is used in cuisine and various other food items. In Japan, bamboo powder is used generally in making standard bread flour and also allows a $3-8 \%$ addition of powder to any food items, Hua (1987). Chinese, bamboo shoot used for making beverages and specific liquors aside from medicines, Qing et al. (2008). Due to have different quality attributes (Pysical, chemical, nutritional and sensory), bamboo shoots reported number of health benefits by lowering blood lipids and fighting heart ailments Shi and Yang, (1992), Satya et al. (2009).

\section{Medicines}

Bamboo shoot has been used in various regions in form of medicine by tribal people in ancient times. With different flavones, glycosides, bamboo shoots have good antioxidant, anti-free-radical and anti-aging properties, it can be used for making capsules and tablets. Shi and Yang, (1992), RFRI, (2008). Bambusa arundinacea species is considered as the excellent source of bamboo manna, which is known to be a good tonic for respiratory disorders. Puri (2003). Bamboo shoots mixed with jaggery are known to induce parturition or abortion Shi and Yang, (1992), Puri (2003). In Java, inside the shoots, sap is used mainly for curing Jaundice Burkill, (1935). Most of Chinese countries used bamboo shoots for treating infection, the juice of fresh bamboo shoots have function of protease activity that helps in digestion of protein. Boiled bamboo shoots used as 
appetizers, decoction of the shoots are used for curing cough and cold, infected sores, ulcers etc. Cost, (1988). Bamboo salt tablets used in Korea, its contain $\mathrm{Cu}, \mathrm{Zn}$ and $\mathrm{Fe}$ are known to help treat certain internal maladies as well as work as natural detoxifying agent with strong anti-microbial property as they provides energy and nutrients to the body Liu, (1992). Korea makes a bamboo sea salt, which have therapeutic values and used as an alternative to table salt in cookery. Bamboo shoots role in cosmetics as a cleaning agent called bamboo bath salts in part of Korea Cost, (1988).

\section{Effect of cooking and heat processing and aging on the nutritive value of bamboo shoots}

Cooking is essential for the proper digestion of bamboo shoots. Cooking also helps the breaking of cell walls in tender vegetables and thus ease digestion of proteins present in them. There are numerous ways in which bamboo shoots are processed and prepared. There is mild hydrolysis and many changes occur during processing of bamboo shoots that accompanying many physical and chemical changes alter the nutritional quality of the shoots. First changes occur in nutrient composition in shoots after boiling, fermentation, canning and during aging have been studied Kumbhare and Bhargava, (2007); Nirmala et al. (2007). There is slight destruction of protein and sugar contents in the shoots after boiling. The ash content also decreases on boiling, fermentation and canning. The losses varies from $21 \%$ after boiling, $16 \%$ after canning and $13 \%$ after fermentation. The carbohydrate content ranges from 4.08 to $6.71 \mathrm{~g} / 100 \mathrm{~g}$ fresh weight and though there was an increase in the content after boiling, there was a substantial increase up to $72 \%$ after fermentation and canning Nirmala et al. (2008). There was no more changesseems to fiber content after boiling but it enhancing remarkably after fermentation and canning Kumbhare and Bhargava, (2007). Some recent studies were determined by Nirmala et al. (2008) that changes seen in the nutrient components in fresh, fermented and canned shoots of a commercially important bamboo, D. giganteus. The freshly harvested shoots are richer in nutrient components compared to canned and fermented shoots. There was an overall decrease of the nutrient components, except the dietary fiber content, during fermentation and canning. Fresh shoots have higher quantities of macronutrients such as amino acids, proteins, carbohydrates, fat and fiber than the fermented and canned shoots, except for vitamins $C$ and vitamin $E$ and minerals such as $\mathrm{Ca}, \mathrm{Fe}, \mathrm{K}$ and $\mathrm{P}$. Vitamin $\mathrm{C}$ and vitamin $\mathrm{E}$ content were highest in raw shoots $(3.27 \mathrm{mg}$ and 0.78 $\mathrm{mg} / 100 \mathrm{~g}$ fresh weight) followed by canned (1.8 $\mathrm{mg}$ and 0.3 $\mathrm{mg} / 100 \mathrm{~g}$ fresh weight) and fermented shoots (1.09 $\mathrm{mg}$ and $0.21 \mathrm{mg} / 100 \mathrm{~g}$ fresh weight). Losses of trace elements occur by leaching when excess of water used in cooking is discarded. Generally the moisture content seems to be high in the canned shoots. Thus, freshly harvested shoots, being nutritionally richer than the fermented shoots are recommended for consumption as food. A slight decomposition in nutrient components were also observed during the aging and harvesting time of youngshoots $\mathrm{Hu},(1975)$; Hu et al, (1986). A study conducted on 5 commercially important bamboos, B. bambos, B. tulda, $D$. asper, $D$. giganteus and $D$. hamiltonii, showed that whereas nutrient components of the shoots were depleted with aging, the dietary fiber and moisture contents increased. Vitamin and mineral contents also decrease in the older shoots. In this way we say that freshly shoots are more superior compare to old emerged shoots as well as its nutritional quality only depend on cooking and heat processing.

\section{Conclusion AND FUtURe Prospective}

Bamboo shoots have immense role as a health food as they have high content of proteins, amino acids, carbohydrates and many important minerals and vitamins and very low fat, so they boost our immune system and keep healthy. Due to their high nutritional values, bamboo shoots are consumed mostly in Asiatic countries for several traditional cuisines of the resion. The fresh or fermented bamboo shoots generally used for making number of ethnic dishes. But shoots should be properly processed as they contain high level of toxic compound. By using appropriate processing method, will not only reduce toxic cyanogenic compound but also retain the nutritional quality.Bamboo shoots have high nutritional composition and contain bioactive compounds, a great promise is that people utilized as a health food. According their multiple role, in different countries various terms popular such as "designer foods" Caragay, (1992), "functional foods" Thomas and Earl, (1994) and "nutraceuticals" De Felice, (1995) have been coined to designate foods for health promotion and disease prevention. India has a bright prospect for bamboo shoot industry. At present time bamboo shoot production is primarily for executing the local needs. Predominantly the effective marketing strategies is one method available of making bamboo shoot products and many potential and prospective customers of insider and outsider countries liking bamboo based traditional dishes as well as maximum profit gain. Intervention of modern micropropagation techniques is also essential to control the falling population of bamboos. The local bamboo shoot industry if properly established will not only help in socioeconomic upliftment of the resion but also generate huge income for the country. Although bamboos are popularized as food items day to day and its commercial production is taken up on a large scale, then it will contribute enormously to rural economies and boost export earnings.

\section{ACKNOWLEDGEMENT}

This research was conducted at Directorate of Research, the C.S. Azad University of Agriculture and Technology, Kanpur under NAHEP Centre for Advanced Agricultural Science and Technology on Nutritional Crops Sponsored by ICAR, New Delhi. The financial assistance is duly acknowledged and thanks for Director Research of the University for providing me with the research support. 


\section{REFERENCES}

Abumweis, S.S. and Jones, P.J.H. (2008). Plant sterols: Natural plant components with potential beneficial health effects. International News on Fats, Oils and Related Materials (INFORM) 18: 825-08.

Awad, A.B. and Fink, C.S. (2000). Phytosterols as anticancer dietary components: Evidence and mechanism of action. J. Nutr. 130: 127-140.

Bao, J. (2006). The nutrition and bioactive function of bamboo shoots. Food Nut. in China. 4: 2-3.

Benzhi, Z., Maoyi, F., Jinzhong, X., Xiaosheng, Y. and Zhengcai, L. (2005). Ecological functions of bamboo forest: Research and application. J. For. Res. 16(2): 143-150.

Bhatt, B.P., Singha, L.B., Sachan, M.S. and Singh, K. (2005). Commercial edible bamboo species of the north-eastern Himalayan region, India. Part II: Fermented, roasted and boiled bamboo shoots sales. J. Bamboo Rattan. 4(1): 13-31.

Biesalski, H.K., Dragsted, L.O., Elmadfa, I., Grossklaus, R., Muller, M., Walter, P. and Weber, P. (2009). Bioactive compounds: Definition and assessment of activity. Nutrition. 25(12): 1202-1207.

Burkill, (1935). Phytosterols as anticancer compounds. Mol. Nut. Food Res. 2: 161-70.

Caitlin and Miles, (2000). Study on bamboo grows naturally or is cultivated in orchard and farms and is one of the natural resources in the international scenario. J. Bamboo Res. 18: 6-11.

Caragay, (1992). Bamboos have multiple role in different countries, various terms popular such as "designer foods or "functional foods". J. Food Sci. Tech. 40: 622-5.

Cost, (1988). Boiled bamboo shoots used as appetizers, decoction of the shoots are used for curing cough and cold, infected sores, ulcers etc. Food Technol. 46(4): 65-73.

Daphne et al. (1996). Bamboo shoots used as a part of regular cookery and are consumed in various forms in many parts of the world. J. Sci. Food Agri. 32: 494-7.

De Felice, (1995). Study on Bamboo shoots have been coined to designate foods for health promotion and disease prevention. Nutrition. 23(13): 1102-1106.

Farooquee et al. (2007). Effects of ingredients and process conditions on 'Amaretti' cookies characteristics. Intl. J. Food Sci. Tech. 43(8): 1395-403.

Fu and Singh et al. (2009). Sour cherry (Prunus cerasus L.) anthocyanins as ingredients for functional foods. J. Biomed Biotech. 5: 253-561.

Giri, S.S. and Janmejoy, L. (1992). Nutrient composition of three edible bamboo species of Manipur. Front Biol. 4: 53-6.

Greijmans et al. (2007). Effect of bamboo shoot fermentation and aging on nutritional and sensory qualities of soibum. J. Food Sci. Tech. 37(4): 423-6.

Hamman, J.H. (2008) and Park (2010). The edible bamboo shoots contain strong unique taste and flavor due to present of typical aroma, bio-flavonoids and antioxidant. Mayo. Clin. Proc. 78: 965-78.

Hu et al. (1986). A study conducted on 5 commercially important bamboos, B. bambos, B. tulda, D. asper, D. giganteus and $D$. hamiltonii, showed that nutrient components of the shoots were depleted with aging and moisture content increased. J. Agric. Food Chem. 45: 3632-4.
Hu, C. (1985). The changes in nutrient composition of bamboo shoots at different ages. In: Recent research on bamboos. Proceedings of the International Bamboo Workshop Hangzhou, China. 14(6): 304-312.

Knechtges (1986). Bamboo shoots product commercially available in China, Japan, Thiland and Malaysia available in different forms such as bamboo pickle, powder, bamboo shoot juice, bamboo beer, vine, bamboo tea and vinegar etc. J. Sci. Food Agri. 32: 494-7.

Kozukue et al. (1998). Functional properties and antimicrobial activity of bamboo (Phyllostachys spp.) extracts. Korean J. Food Preser. 8: 475-80.

Kris-Ethertonn et al. (2004). Polyphenols: Chemistry, dietary sources, metabolism and nutritional significance. Nut. Rev. 56: 317-33.

Kumbhare, V. and Bhargava, A. (2007). Effect of processing on nutritional value of central Indian bamboo shoots. Part 1. J. Food Sci. Tech. 44(1): 29-31.

Lewington, A. (1999). Bamboos are most valuable and alternative crop with multiple uses and benefits. 24(1): 83-90.

Liu. (1992). Bamboo salt tablets used in Korea, its contain Cu, Zn and $\mathrm{Fe}$ are known to help treat internal maladies as well as work as natural detoxifying agent. Food Chem. 87(3): 361-367.

Lobovikov (2003). Thialand, India, China and Taiwan used bamboo (Phyllostachys spp.) for domestic consumption as food items. Korean J. Food Preser. 8: 475-80.

Nirmala et al. (2007). Studies on slight destruction of protein and sugar contents in the shoots after boiling, the ash content also decreases on boiling, fermentation and canning. Journal of Food Science and Technology. 23(6): 332-339.

Nirmala et al. (2008). Changes in nutrient components during aging of emerging juvenile bamboo shoots. International Journal of Food Science and Nutrition. 58: 345-52.

NMBA (2009). Engineering Resource Group, Bangalore, reported that bamboo shoots used in the North and South Indian Cuisine as a healthy diets. 42(1): 41-45.

Pandey and Pandey. (2008). The antioxidant, angiotensin converting enzyme inhibition activity and phenolic compounds of bamboo shoot extracts. Food Science and Technology. 43(4): 655659.

Park and John (2012). In Northeast states bamboo shoots are taken either fresh or dried, fermented or pickled forms during offseason. Molecular Nutrition and Food Research. 51(2): 161-170.

Puri. (2003). Bamboo shoots mixed with jiggery are known to induce parturition or abortion. The Journal of the American Medical Association. 294(22): 2849-2857.

Qing et al. (2008). Chinese bamboo shoot used for making beverages and specific liquors aside from medicines. Curr. Sci. 84: 1544-7.

Qiu. (1992). Bamboo shoots based diet are rich source of fat, sugar, fibre and inorganic salts and contain 17 amino acids, 8 of are essential for the human body. Food Nut. in China. 5: 2-3.

RFRI. (2008). Bambusa arundinacea species is considered as the excellent source of bamboo manna, which is known to be a good tonic for respiratory disorders. J. For Res. 15(2): 143-148. 
Rostagno et al. (2010). Plant food contains many bioactive compounds, these physiologically active compounds referred to as "phytochemicals". Front. Biol. 4: 53-6.

Sarangthem, K. and Singh, T.N. (2003). Transformation of fermented bamboo (Dendrocalamus asper) shoots into phytosterols by microorganisms. J. Food Sci. Tech. 40: 622-5.

Satya et al. (2009). Different quality attributes (Physical, chemical, nutritional and sensory) of bamboo shoots reported number of health benefits by lowering blood lipids and fighting heart ailments. The American Journal of Clinical Nutrition. 69(1): 30-40.

Shi and Yang. (1992). Cholesterol- lowering effects of dietary fibre with respects to nutritional and anti-nutritional components. The American Journal of Clinical Nutrition. 69(1): 30-40.

Tai and Fu et al. (1985). Two major species of edible bamboo shoots which are famous in Thiland and Taiwan such as Dendrocalamus lactiferous and Bambusa oldhami. J. Agric. Food Chem. 46: 3630-4.

Tapiero, et al. (2001). Children and women before menopause during pregnancy while nursing, require high amount of iron. Trends Food Sci. Technol. 6: 59-61.
Thomas and Earl. (1994). Nutritional summary for bamboo shoots, canned drained solids. U.S. Department of Agriculture, USDA, Nutrient Database for Standard Reference, Release 18. Available rom: www.nal.usda.gov/fnic/foodcomp/search/. Visuphaka, K. (1985). The Role of Bamboo as a Potential Food Source in Thailand, In Proceedings of the International Bamboo. Recent Research on Bamboos, China. 22(6): 330-336.

Visuphaka, K. (1985). The role of bamboo as a potential food source in Thailand. Proceedings of the International Bamboo Workshop, Hangzhou, China: Recent Research on Bamboos. 14(6): 301-303.

Yang et al. (2008). At present, over two million tons of edible bamboo shoots are consumes in the world in each year. Food Sci. 26: 222-7.

Yuming and Jiru (1999). The properties of bamboo shoots were recorded in the pharmaceutical text book, "It's slightly cold, sweet, non-toxic and cn be served as a daily dish". The Journal of the American Medical Association. 294 (22): 2849-2857. 